\title{
Food consumption, eating behaviour and self-esteem among single $v$. married and cohabiting mothers and their 12-year-old children
}

\author{
Kristina Elfhag ${ }^{1,2, *}$ and Finn Rasmussen ${ }^{1,2}$ \\ ${ }^{1}$ Child and Adolescent Public Health Epidemiology Group, Department of Public Health Sciences, Karolinska \\ Institutet, 17176 Stockholm, Sweden: ${ }^{2}$ Division of Epidemiology, Stockholm Center of Public Health, \\ 17176 Stockholm, Sweden
}

Submitted 29 August 2007: Accepted 3 April 2008: First published online 19 May 2008

\begin{abstract}
Objective: Being a single mother may have implications for health behaviours that can also affect the child. More information about the food intakes and body weights in single $v$. married/cohabiting mothers and in their children is needed. Psychological dimensions of eating behaviour and self-esteem are also of relevance to explore for single mothers and their children.

Design: Food style patterns were assessed by self-reported consumption of fruits, vegetables, sweets and soft drinks. Eating behaviour was measured by the Dutch Eating Behaviour Questionnaire and self-esteem by the Harter self-perception scale. The participants were 1781 mothers and their 12-year-old children, of whom 278 mothers (16\%) were single.

Results: Single mothers had lower intake of fruits and vegetables and lower selfworth compared to the married and cohabiting mothers, controlling for age, education and BMI. Although single mothers did not have a higher BMI, their daughters were heavier than girls from complete families. Daughters to single mothers furthermore had a higher intake of soft drinks, higher levels of restrained eating and lower self-worth. No such difference was found for the boys.

Conclusions: A lower sense of self-worth and lower intake of fruit and vegetables in single mothers could be seen in the context of the social disadvantages and less social support. Girls may be more inclined to be affected by family status than the boys, seen in a more unfortunate psychological pattern and a higher body weight. Boy's health behaviours may be more unaffected by living in single families.
\end{abstract}

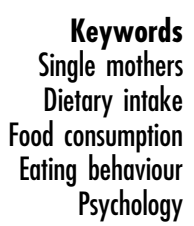

The number of single-parent families has increased during the last decades and is fairly common today. In Sweden, at least one-fourth of 17-year-old youngsters have experienced a separation between their parents ${ }^{(1)}$. It is in particular households with single mothers that have increased. Even though custody is now mainly shared between the parents, only $20 \%$ of the children live as much with the father as the mother. Most children with separated parents live permanently with the mother ${ }^{(1)}$.

Being a single mother may imply more demands seen in life stress and less social support ${ }^{(2)}$. Concerning health behaviours, prior literature has suggested that being single or divorced/separated is associated with lower consumption of vegetables ${ }^{(3-5)}$ and according to one study lower consumption of fruits as well ${ }^{(3)}$.

A parent-child association for food intakes has furthermore been shown ${ }^{(6-8)}$. Children's food consumption is to some extent determined by their parent's consumption.
That is, if the parents have higher healthy or unhealthy food choices, the child is more likely to consume more of these food groups as well. In the parents, however, psychological aspects such as eating behaviour and self-esteem were found to be among the determinants for their food choices ${ }^{(6)}$. These psychological aspects should therefore be included in the study of healthrelated patterns.

Deeper understanding of differences in patterns of food intakes and body weights in single $v$. married/ cohabiting mothers as well as in their children is needed. Psychological dimensions of eating behaviour and selfesteem are also of relevance to explore for single mothers and their children.

The aim of the study is to compare food consumption and psychological characteristics for single mothers and their children $v$. married/cohabiting mothers and their children. As there is a parent-child association for 
food choices, an additional aim is to compare whether these links are of greater magnitude for the single than the complete families, as living with the mother only may hypothetically imply a closer bonding and greater influence.

\section{Methods}

\section{Sample and procedure}

The PITCH (Parental Influences on Their Children's Health) data set was created by a record linkage between several Swedish national registers in the year 2000 (the Medical Birth Register, the Military Service Conscription Register and the Statistics Sweden's Multi-Generation Register). From the database, boys and girls born in Sweden during 1988 and 1989, whose biological parents were born in a Scandinavian country, living in Sweden and alive during 1999, were selected. The original study design included three groups of overweight patterns in the parents: (i) an overweight father and normal weight mother; (ii) an overweight mother and normal weight father; and (iii) both parents being normal weight. Two-thirds of the mothers were thus normal weight according to the register data the groups were based on. This furthermore implies that the mean BMI of the parents is higher than in the general Swedish population. In the study design households with complete families and single mother families were included. The response rate was $33.5 \%$. Analyses of missing data due to non-participation or incompletely filled questionnaires showed no difference in BMI for the parents, but a higher proportion of welleducated parents among the respondents ${ }^{(9)}$. Additional analyses of missing data for single and cohabiting households revealed quite similar levels of response rates. In the responders, $16 \%$ were single mothers as compared to $18 \%$ in the non-responders.

The sample consists of 1826 mothers and their children of whom 1781 mothers and children are included in the present study as the data were complete for them. The children were all approximately 12 years old (Table 1 ) at the time of the data collection for this study. Different questionnaires adapted for adults and children were sent to parents and child separately, accompanied by a letter with information. According to the information in the letters, the questionnaire should be completed by the parent or child on their own.

\section{Civil status}

Information about the parent's civil status was derived from the Swedish Register of the Total Population. The information was valid for the start of the year 2000 when the data file was created and the questionnaires sent out to the families. The variables included married or partnership, cohabiting or single. The two first variables were collapsed into one variable covering marriage, partnership and cohabiting with a partner.

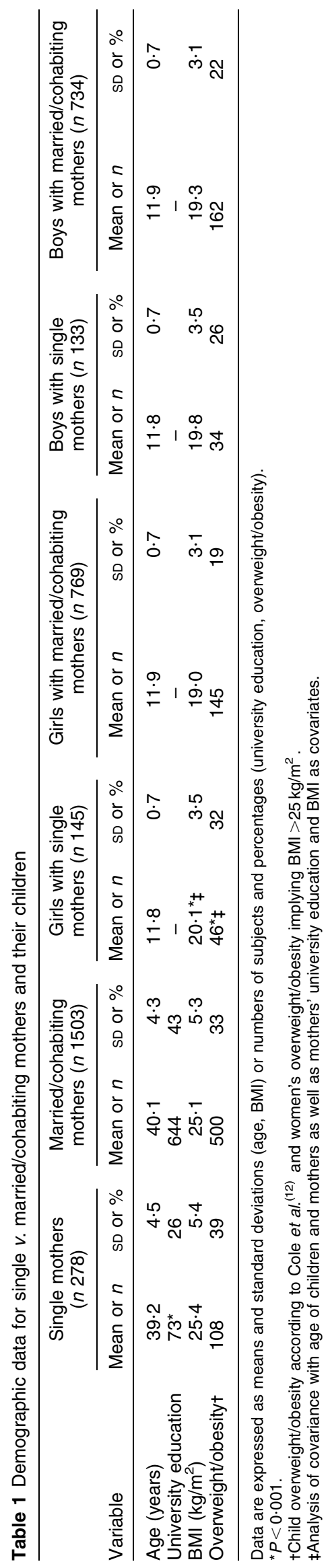




\section{Education}

The parents' educational level was self-reported as an item with six alternative levels, ranging from less than 9 years of primary school education to 3 or more years of university education. Education was recoded into a dichotomous variable based on a cut-off for university level and higher.

\section{Food intake}

The assessment of healthy and unhealthy food intake was performed using an FFQ of the type inquiring only about frequencies of food types without specification of portion size ${ }^{(10)}$, but in a new version adapted for the study. The typical healthy and unhealthy foods, fruits, vegetables, sweets and soft drinks, were chosen from a more extensive list of food intakes (eleven types of foods) included in a questionnaire. All kinds of sweets were assessed as one variable, using the Swedish word for 'sweets' that includes all sorts of candies and chocolate. Soft drinks with sugar and with artificial sweeteners were collapsed into one soft drink variable, as they were both considered as markers of unhealthy foods. Artificially sweetened soft drinks adds no nutritional value, and a predisposition to sweet taste is maintained by an exposure to sweetened drinks ${ }^{(11)}$, which may be the case for artificial sweeteners as well. Artificially sweetened soft drinks were therefore included in the overall soft drink measure, indicating an unhealthy food style. Collapsing both types of soft drinks into one variable also gave a better distribution of the data, as soft drink consumption was generally quite low. Food intakes were measured as consumption of the respective food alternatives in number of days during the last week. The alternatives were no intake, $1 \mathrm{~d} /$ week, $2 \mathrm{~d} /$ week, 3-4 d/week, 5-6 d/week and daily. To enable data on an interval scale, these alternatives were coded as $0,1,2,3 \cdot 5$, $5 \cdot 5$ and 7 , respectively. The numerical range for the food intakes is thus 0 to 7 , as the food could have been consumed from none to all 7 days of the week.

\section{Body weight and body beight}

Body weight and height for adults were self-reported and constituted the most recent weights, whereas the weights from the national databases were past weights and not used for the analyses in this study. Body weights and heights for the children were collected from the school health records or, if the date of measurement differed by more than \pm 6 months from the date when the children answered the questionnaire, from the questions answered by the parents. The mother's information about the child's body weight and height was then used, and if this was not available, the father's information about the child was used. The height and weight data were collected from school health records for $49 \%$ of the children, from the mother for $47 \%$ and from the father for $4 \%$. The children's body weights were categorised according to reference values for child overweight and obesity as established by Cole et al. $^{(12)}$.

\section{Eating behaviour}

Eating behaviour was measured using the Dutch Eating Behaviour Questionnaire (DEBQ) ${ }^{(13)}$. The DEBQ consists of subscales for Restrained Eating, Emotional Eating and External Eating. The numerical ranges for the DEBQ scales are 1 to 5 . A higher score represent a more pronounced level of the eating behaviour measured with the scale.

The DEBQ has previously been used in a sample of around 10000 Dutch adolescents aged 11-16 years (mean age 13 years) ${ }^{(14)}$. The psychometric properties for the DEBQ in this age group were good, as seen in Cronbach's $\alpha$ and a factor analysis that confirmed the factor structure observed in adults for the three scales.

\section{Self-esteem}

Self-esteem was measured according to a model proposed by Harter ${ }^{(15)}$, using the Harter Self-Perception Profile for Adults (SPPA) ${ }^{(16)}$ for the parents and the Harter Self-Perception Profile for Children (SPPC) ${ }^{(17,18)}$ for their children. The SPPA and SPPC give subscales as well as a global self-worth score. The global self-worth score was used in our analyses. The numerical range for this score is 1 to 4 . A higher score represents higher self-worth.

\section{Statistical analysis}

Demographic variables (age, education and BMI) were tested for single $v$. married/cohabiting mothers and their children with the $t$-test and Pearson $\chi^{2}$ test. Differences in food frequencies and psychological variables in the two groups of mothers and in their children were tested using analysis of covariance (ANCOVA) controlling for the mother's education, age and BMI. The BMI of the children to single $v$. married/cohabiting mothers was tested with ANCOVA controlling for the children's age aside from the mother's education, age and BMI, as there was some variability in age at which the weights were collected and as BMI differs with age in children. Differences in strengths for the mother-child correlations (partial correlations controlling for the mother's education, age and BMI) for single $v$. married/cohabiting mothers were analysed using a test for significant differences between independent correlations ${ }^{(19)}$. For the statistical analyses, the Statistical Package for Social Sciences (SPSS for Windows version $13 \cdot 0$; SPSS Inc., Chicago, IL, USA) was used.

\section{Results}

\section{General results}

Sixteen per cent ( $n$ 278) of the women were single and $84 \%$ ( $n$ 1503) were married or cohabiting. Single mothers had lower education, with $26 \%$ having achieved a university 
education, compared to $43 \%$ in married/cohabiting women, as shown in Table 1 . Age and BMI did not differ between the two groups of women. The girls with single mothers had a higher BMI $(F=3.53, P<0 \cdot 001)$ and a higher proportion of child overweight/obesity $\left(\chi^{2}=12 \cdot 2\right.$, $P<0 \cdot 001$ ). A smaller and non-significant difference for BMI and child overweight/obesity was found for boys (BMI: $F=0.218, \quad P=0 \cdot 063$, Child overweight/obesity: $\left.\chi^{2}=0 \cdot 8, P=0 \cdot 376\right)$. Children's mean heights were $153 \cdot 5$ (sD $8 \cdot 2) \mathrm{cm}$ for girls and $153(\mathrm{sD} 8 \cdot 5) \mathrm{cm}$ for boys. The girls' mean weights were 45.5 (SD 10.1) $\mathrm{kg}$ and the boys' weights were $45 \cdot 7$ (sD 10.7) $\mathrm{kg}$.

\section{Food frequencies and psychological characteristics}

The differences in food frequencies, eating behaviour and self-esteem are shown in Table 2. Statistically significant differences between single and cohabiting mothers were found for fruits, vegetables and self-esteem. Single mothers had lower levels of fruit and vegetable intake, in particular lower intake of fruits. The single mothers furthermore had clearly lower self-esteem. The corresponding results for children are shown in Table 3. Daughters to single mothers had somewhat higher intake of soft drinks, higher levels of restrained eating and lower self-worth. No significant differences were found for the boys.

\section{Differences in correlations for motber-child associations}

Correlations for mother-child associations for food frequencies, eating behaviour and self-esteem that have been reported earlier ${ }^{(6)}$ were now performed separately for single $v$. cohabiting mothers. Separate analyses were also performed for boys and girls. The correlations for the single $v$. the married/cohabiting mother-child pair were in the next step tested for significant differences. The correlations for the two groups did not differ at large from each other at a statistically significant level. The only difference found was a stronger mother-son association for fruits in single mothers (single mother-son: $r=0 \cdot 43$, cohabiting mother-son: $r=0 \cdot 15, Z=3 \cdot 2, P=0 \cdot 001)$.

\section{Discussion}

\section{Single motbers}

Single mothers had on average a lower education, and further analyses were controlled for this well-known

Table 2 Food frequencies, eating behaviour and self-esteem in single $v$. married/cohabiting mothers

\begin{tabular}{|c|c|c|c|c|c|c|}
\hline \multirow[b]{2}{*}{ Variable } & \multicolumn{2}{|c|}{ Single mothers ( $n$ 278) } & \multicolumn{2}{|c|}{ Married/cohabiting mothers ( $n$ 1503) } & \multirow[b]{2}{*}{$F^{*}$} & \multirow[b]{2}{*}{$P$} \\
\hline & Mean & SD & Mean & SD & & \\
\hline Fruits (d/week) & $4 \cdot 7$ & $2 \cdot 2$ & $5 \cdot 5$ & $2 \cdot 0$ & $19 \cdot 3$ & 0.000 \\
\hline Vegetables (d/week) & $5 \cdot 6$ & $1 \cdot 9$ & $6 \cdot 0$ & $1 \cdot 6$ & $5 \cdot 8$ & 0.016 \\
\hline Sweets (d/week) & $2 \cdot 1$ & $1 \cdot 7$ & $2 \cdot 1$ & $1 \cdot 5$ & 0.5 & NS \\
\hline Soft drinks (d/week) & $0 \cdot 9$ & $1 \cdot 5$ & $0 \cdot 7$ & $1 \cdot 1$ & $2 \cdot 7$ & NS \\
\hline \multicolumn{7}{|l|}{ DEBQ } \\
\hline Restrained eating & $2 \cdot 7$ & 0.9 & $2 \cdot 6$ & $0 \cdot 8$ & $0 \cdot 9$ & NS \\
\hline Emotional eating & $2 \cdot 0$ & $0 \cdot 8$ & 1.9 & $0 \cdot 7$ & $2 \cdot 5$ & NS \\
\hline External eating & $2 \cdot 8$ & $0 \cdot 6$ & $2 \cdot 8$ & 0.5 & $0 \cdot 8$ & NS \\
\hline Global self-worth & $2 \cdot 9$ & 0.6 & $3 \cdot 1$ & 0.5 & $11 \cdot 0$ & 0.001 \\
\hline
\end{tabular}

DEBQ, Dutch Eating Behaviour Questionnaire.

${ }^{*}$ Analysis of covariance with age, university education and BMI as covariates.

Table $3 \mathrm{BMI}$, food frequencies, eating behaviour and self-esteem in children to single $v$. married/cohabiting mothers

\begin{tabular}{|c|c|c|c|c|c|c|c|c|c|c|c|c|}
\hline \multirow[b]{2}{*}{ Variable } & \multicolumn{2}{|c|}{$\begin{array}{l}\text { Girls with } \\
\text { single mothers } \\
(n 145)\end{array}$} & \multicolumn{2}{|c|}{$\begin{array}{c}\text { Girls with married/ } \\
\text { cohabiting mothers } \\
(n 769)\end{array}$} & \multirow[b]{2}{*}{$F^{*}$} & \multirow[b]{2}{*}{$P$} & \multicolumn{2}{|c|}{$\begin{array}{l}\text { Boys with } \\
\text { single mothers } \\
(n 133)\end{array}$} & \multicolumn{2}{|c|}{$\begin{array}{c}\text { Boys with married/ } \\
\text { cohabiting mothers } \\
(n \text { } 734)\end{array}$} & \multirow[b]{2}{*}{$F^{\star}$} & \multirow[b]{2}{*}{$P$} \\
\hline & Mean & SD & Mean & SD & & & Mean & SD & Mean & SD & & \\
\hline Fruits (d/week) & $4 \cdot 5$ & $2 \cdot 2$ & $4 \cdot 7$ & $2 \cdot 2$ & 0.9 & NS & $3 \cdot 7$ & $2 \cdot 4$ & $4 \cdot 1$ & $2 \cdot 3$ & $2 \cdot 5$ & NS \\
\hline Vegetables (d/week) & $4 \cdot 4$ & $2 \cdot 2$ & $4 \cdot 7$ & $2 \cdot 2$ & 0.7 & NS & $4 \cdot 1$ & $2 \cdot 3$ & $4 \cdot 4$ & $2 \cdot 3$ & $0 \cdot 7$ & NS \\
\hline Sweets (d/week) & $2 \cdot 3$ & $1 \cdot 6$ & $2 \cdot 2$ & 1.5 & 0.2 & NS & $2 \cdot 3$ & $1 \cdot 6$ & $2 \cdot 2$ & 1.5 & 0.5 & NS \\
\hline $\begin{array}{l}\text { Soft drinks (d/week) } \\
\text { DEBQ }\end{array}$ & 1.9 & 1.5 & $1 \cdot 6$ & $1 \cdot 4$ & $4 \cdot 2$ & 0.041 & $1 \cdot 9$ & $1 \cdot 7$ & $1 \cdot \overline{5}$ & $1 \cdot 7$ & 0.3 & NS \\
\hline Restrained eating & $1 \cdot 8$ & 0.7 & $1 \cdot 6$ & $0 \cdot 7$ & $5 \cdot 3$ & 0.021 & 1.5 & $0 \cdot 7$ & 1.5 & $0 \cdot 7$ & 0.04 & NS \\
\hline Emotional eating & $1 \cdot 7$ & $0 \cdot 6$ & $1 \cdot 6$ & 0.6 & 0.1 & NS & $1 \cdot 6$ & $0 \cdot 6$ & $1 \cdot 6$ & 0.5 & 0.01 & NS \\
\hline External eating & $3 \cdot 0$ & $0 \cdot 6$ & $2 \cdot 9$ & 0.6 & $1 \cdot 3$ & NS & $3 \cdot 0$ & $0 \cdot 7$ & $3 \cdot 0$ & 0.6 & 0.07 & NS \\
\hline Global self-worth & $3 \cdot 4$ & $0 \cdot 6$ & $3 \cdot 5$ & 0.5 & $5 \cdot 6$ & 0.018 & 3.5 & 0.6 & $3 \cdot 6$ & 0.5 & $2 \cdot 3$ & NS \\
\hline
\end{tabular}

DEBQ, Dutch Eating Behaviour Questionnaire.

${ }^{*}$ Analysis of covariance with age, university education and BMI as covariates. 
determinant of health behaviours. The Swedish single women had a lower consumption of fruit and vegetables, which corresponds to prior literature ${ }^{(3)}$ although the lower intake of fruits, that was most obvious in our sample, has not been reported as often as a lower consumption of vegetables. A lower sense of self-worth was furthermore seen for single mothers. These findings should be placed in the context of possible social disadvantages for single mothers. Many single mothers have a financial hardship in spite of being more likely to be employed ${ }^{(20)}$, and they have higher rates of depression, anxiety and depressive features ${ }^{(21)}$. Social disadvantages, lack of social support and stress have been found to account for these higher rates of depression in single mothers ${ }^{(2,21)}$. The fact that single mothers are more likely to seek professional help for their mental health problems, independent of the depression per $\mathrm{se}^{(22)}$, also suggests the role of lacking social support in the life situation. The lower self-esteem we found in the single mothers is an important aspect of such a depressive functioning.

We have previously shown that higher self-esteem is a factor in higher consumption of fruit and vegetables ${ }^{(6)}$. A possibility is that the association found in the current analyses is due to a lower trust in own capacity to adopt a healthy eating pattern. A lower sense of self-worth can furthermore imply caring less about the personal health and well-being, decreasing the healthy food intakes.

Although fruit and vegetable intake was lower in the single mothers, they did not have a higher consumption of the unhealthier alternatives, sweets and soft drinks. The finding on vegetables could indicate fewer prepared meals, replaced by faster alternatives. Several food groups that were not covered by our measures could be of interest for future research.

Finally it should also be mentioned that research findings that instead suggest a more optimistic psychological situation in single women exist as well. Single women perceive themselves as growing more attractive over time, compared to married women, with little age differences in the associations ${ }^{(23)}$.

\section{Children to single mothers}

Sixteen per cent of the children were living with a single mother. Although single mothers did not have a higher BMI, their daughters were heavier than girls from complete families. This is in agreement with earlier findings showing that single-mother families increase the likelihood of the child being overweight or obese ${ }^{(24)}$, although for the boys this difference did not reach a statistically significant level in our sample.

Daughters to single mothers furthermore had a higher intake of soft drinks, higher restrained eating and lower self-worth. No such differences were found for the boys. The daughters may be more affected by the single-parent family situation than the sons. The girls could be more vulnerable to the lack of social support and worse prerequisites in the single families. Furthermore, children identify themselves mostly with the parent of the same sex during childhood, as they develop their gender identity. The girls' identification with the mother as a female model during childhood may be yet another factor accounting for the differences, as the girl may have incorporated the lower self-esteem and possibly lower care for health perceived in her mother, resulting in lower self-esteem and behaviours, leading to a higher weight gain. The higher restrained eating in the daughters to single mothers may reflect attempts to counteract the higher body weight, or a problematic eating behaviour reflecting body dissatisfaction.

The sons appeared to be more unaffected concerning health behaviours in the single families. Boys are of course less inclined to identify with their mothers as they identify with the father or another adult male for developing a male identity. Boys may possibly also be less sensitive to the social situation within the family. They may for example instead be more influenced by the surrounding environment.

Although the single mothers had a lower intake of fruits and vegetables, this was not seen for their children, in spite of the association that exists between mothers' and children's food intakes ${ }^{(6)}$. The public lunch meals in school in Sweden may account for this lack of difference between children to single $v$. complete families. These lunch meals are usually complete cooked meals of good nutritional value, with vegetables included or served on the side. Fruits may sometimes also be included. The public school meals are of importance for providing all children food of good nutritional value at least once a day, irrespective of their background, and can therefore have a particular relevance for children who would otherwise not have complete meals at home. An alternative interpretation that cannot be excluded, however, is that single mothers may be concerned to provide their children with fruits and vegetables even if they have a lower consumption themselves.

Parent-child associations for food consumption and psychological characteristics have been shown in prior research $^{(6)}$, and these links did not differ for single $v$. cohabiting mothers and their children, except for a stronger mother-son association for fruits in single mothers. It therefore seems that living with a single mother does not mean a stronger similarity in food consumption or psychological characteristics that could have been anticipated if there was a closer bonding between the child and mother in a single than in a complete family.

\section{Limitations}

A limitation in the study is that the food intakes were measured as consumption of the food types in number of days during the last week, and did not take portion sizes into account. This is therefore a crude measure. However, having consumed a food type at all or not may, on the 
other hand, likely be more correctly recalled and reported than more exact amounts of food consumed. Weekly food frequencies can be regarded as a marker of food styles and an alternative to more detailed dietary assessments in large-scale studies.

Another limitation with the study was the low response rate of $33.5 \%$, with a higher proportion of well-educated parents among respondents. This means fruit and vegetable consumption that is known to be linked to a higher education was likely more frequent than in the population at large. However, the response rates for single $v$. cohabiting mothers directly addressed in the study were similar. The BMI for the women in our sample was higher than for the population at large due to the original study design, but as two-thirds of the women were normal weight the generalisability is likely still good.

The contribution of our study includes enhancing the awareness of some inequalities for single-parent families concerning health behaviours, in particular for mothers and daughters. A possible vulnerability in daughters including a greater body weight or weight increase would be important to explore in more detail in future research. A social factor such as family status can have implications for health behaviours and could be considered in public health for children and adults.

\section{Acknowledgements}

Conflict of interest: The authors declare that they have no conflict of interest.

Funding support: This study was supported by a grant to F.R. from the Swedish Council for Social Research (grant number F0123/2000).

Authors' contributions: K.E. developed the hypotheses for this specific study, performed the statistical analyses and drafted the paper. F.R., principal investigator of the PITCH study, provided input to the analytic work, revision of the draft and the final version of the paper.

Acknowledgements: The contributions of Per Tynelius, with regard to sampling and creation of the database, and Sanna Tholin with regard to measurements and the creation of the database are greatly appreciated.

\section{References}

1. Statistics Sweden (2007) Living conditions. http:// www.scb.se (accessed September 2007).

2. Cairney J, Boyle M, Offord DR \& Racine Y (2003) Stress, social support and depression in single and married mothers. Soc Psychiatry Psychiatr Epidemiol 38, 442-449.

3. Billson H, Pryer JA \& Nichols R (1999) Variation in fruit and vegetable consumption among adults in Britain. An analysis from the dietary and nutritional survey of British adults. Eur J Clin Nutr 53, 946-952.
4. Devine CM, Wolfe WS, Frongillo EA Jr \& Bisogni CA (1999) Life-course events and experiences: association with fruit and vegetable consumption in 3 ethnic groups. J Am Diet Assoc 99, 309-314.

5. Pollard J, Greenwood D, Kirk S \& Cade J (2001) Lifestyle factors affecting fruit and vegetable consumption in the UK Women's Cohort Study. Appetite 37, 71-79.

6. Elfhag K, Tholin S \& Rasmussen F (2008) Consumption of fruit, vegetables, sweets and soft drinks are associated with psychological dimensions of eating behaviour in parents and their 12-year-old children. Public Health Nutr (In the Press)

7. Longbottom PJ, Wrieden WL \& Pine CM (2002) Is there a relationship between the food intakes of Scottish 5(1/2)8(1/2)-year-olds and those of their mothers? J Hum Nutr Diet 15, 271-279.

8. Bere E \& Klepp KI (2004) Correlates of fruit and vegetable intake among Norwegian schoolchildren: parental and self-reports. Public Health Nutr 7, 991-998.

9. Eriksson M, Nordqvist T \& Rasmussen F (2008) Associations between parents' and 12-y-old children's sport and vigorous activity: the role of athletic competence. $J$ Phys Activ Health 5, 359-373.

10. Khani BR, Ye W, Terry P \& Wolk A (2004) Reproducibility and validity of major dietary patterns among Swedish women assessed with a food-frequency questionnaire. J Nutr 134, 1541-1545.

11. Beauchamp GK \& Moran M (1982) Dietary experience and sweet taste preference in human infants. Appetite 3, 139-152.

12. Cole TJ, Bellizzi MC, Flegal KM \& Dietz WH (2000) Establishing a standard definition for child overweight and obesity worldwide: international survey. BMJ 320, $1240-1243$.

13. van Strien T, Frijters JE, Bergers GPA \& Defares PB (1986) The Dutch Eating Behaviour Questionnaire (DEBQ) for assessment of restrained, emotional and external eating behaviour. Int J Eat Disord 5, 747-755.

14. Snoek HM, van Strien T, Janssens JM \& Engels RC (2007) Emotional, external, restrained eating and overweight in Dutch adolescents. Scand J Psychol 48, 23-32.

15. Harter S (1983) Developmental perspectives on the self-system. In Handbook of Child Psychology, vol. IV: Socialization, Personality, and Social Development, pp. 275-285 [PH Mussen, editor]. New York: Wiley.

16. Messer B \& Harter S (1986) Manual for the Self-perception Profile. Denver, CO: University of Denver.

17. Harter S (1988) Manual for the Self-perception Profile for Adolescents. Denver, CO: University of Denver.

18. Wichstrom L (1995) Harter's self-perception profile for adolescents: reliability, validity, and evaluation of the question format. J Pers Assess 65, 100-116.

19. Howell DC (2002) Statistical Methods for Psychology. Belmont, CA: Duxbury Press.

20. Brown GW \& Moran PM (1997) Single mothers, poverty and depression. Psychol Med 27, 21-33.

21. Targosz S, Bebbington P, Lewis G, Brugha T, Jenkins R, Farrell M \& Meltzer H (2003) Lone mothers, social exclusion and depression. Psychol Med 33, 715-722.

22. Cairney J \& Wade TJ (2002) Single parent mothers and mental health care service use. Soc Psychiatry Psychiatr Epidemiol 37, 236-242.

23. Giesen CB (1989) Aging and attractiveness: marriage makes a difference. Int J Aging Hum Dev 29, 83-94.

24. Gibson LY, Byrne SM, Davis EA, Blair E, Jacoby P \& Zubrick SR (2007) The role of family and maternal factors in childhood obesity. Med J Aust 186, 591-595. 